\title{
A gestão dos recursos hídricos na França e no Brasil com foco nas bacias hidrográficas e seus sistemas territoriais
}

DosSiER DAS ÁGUAS : GESTÃo Do PATRIMÔNIO HÍDRICO

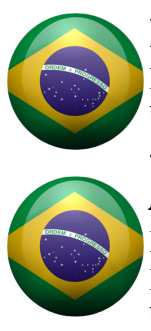

\section{Luci Merhy Martins Braga}

Doutoranda e pesquisadora do Laboratório de Engenharia de Empreendimentos — Labore / DRH-FECUnicamp. Mestre em Engenharia Civil, Engenheira Sanitarista. Jundiaí [São Paulo] Brasil. $<$ l.maerhy@terra.com.br>.

\section{André Munhoz de Argollo Ferrão}

Professor Livre Docente do Departamento de Recursos Hídricos da FEC-Unicamp. Coordenador do Labore. Doutor em Arquitetura e Urbanismo, Mestre em Engenharia Agrícola. Engenheiro Civil, Arquiteto e Urbanista. Campinas [São Paulo] Brasil.<argollo@fec.unicamp.br>.

\section{Resumo}

Este trabalho apresenta a gestão dos recursos hídricos na França e no Brasil salientando a semelhança nos seus conceitos, destacando a experiência francesa como importante referência na institucionalização de novas práticas gestoras, bem como o cenário no Brasil não apenas da constituição dos novos aparatos gestores estaduais, mas também da própria formulação da Política Nacional de Recursos Hídricos. Na França a CLE (Comissão Local de Água) possui um papel de grande importância e participação dentro dos comitês de bacia, e a reunião de governos municipais em torno de uma bacia hidrográfica facilita o processo decisório quanto aos investimentos em saneamento comuns a mais de um município. Esta seria a grande diferença entre os dois modelos de gestão, pois no Brasil não existe a instância de uma comissão local de água, e os municípios se envolvem muito pouco com os comitês de bacia. Os governos, em comum acordo, podem decidir pela concessão dos serviços públicos em seus territórios, amenizar ou mesmo evitar problemas e reduzir o risco de desastres relacionados com a água.

\section{Palavras-chave}

Recursos hídricos, bacia hidrográfica, desenvolvimento regional, governança das águas, gestão integrada.

\section{The water resources management in France and Brazil with focus on water basins and its territorial systems}

\begin{abstract}
This paper presents the management of water resources in France and Brazil by the similarity in their concepts on the management of water resources, and features the French experience as an important reference in the institutionalization of new management practices and Brazil as the basis for establishing not only the new state management apparatuses, but also the very formulation of the National Water Resources Policy. In France the CLE (Local Commissions of Water) have great importance and participation within the basin committees and, the meeting of municipal governments around a watershed facilitates decision making as to investments in common sanitation to more of a municipality. This would be an important difference between the two terms: in Brazil the "CLE" instance doesn't exist, and mayors engage very little with the basin committees. Governments, by agreement, may decide to award public services in their territories and alleviate problems and prevent disasters.
\end{abstract}

\section{Keywords}

Water resources, watershed, regional development, water governance, integrated management. 


\section{Introdução}

A água é um elemento natural que quando se lhe atribuem valor econômico converte-se em recurso; neste caso "recurso hídrico". Como tal, para sua preservação no contexto das políticas públicas de desenvolvimento, a água deveria ser imediatamente associada ao conceito de patrimônio no âmbito dos planos diretores municipais e de bacia hidrográfica, que regulam o uso e ocupação do solo, a revitalização dos rios e a transformação das cidades. A abordagem temática da água conquistou grande abrangência científica e política no decorrer das últimas três décadas. No Brasil, como em muitos países, o uso desordenado dos recursos hídricos pode ser relacionado diretamente com o aumento do risco de desastres, causando grandes dificuldades inclusive para o consumo humano. Com o crescimento demográfico e econômico, os usos da água se multiplicaram fazendo crescer a demanda por esse bem. A escassez fica cada vez mais atrelada a dois fatores: a disponibilidade e a demanda. A crise se agrava, em parte devido ao modelo atual de produção e consumo desenfreado da água, que reconhecidamente é um bem patrimonial e um recurso estratégico essencial ao desenvolvimento socioeconômico de todos os países.

Classificada por muitos como ouro azul ou mesmo petróleo do século XXI, a água segue ganhando abrangência na agenda política contemporânea, precisamente por sua importância estratégica para a produção econômica (MARTINS, 2008, p. 02).

A presença de representantes da comunidade e de instituições nos processos de gestão do território de uma bacia hidrográfica com foco no tripé "efetividade, eficácia e eficiência" é essencial desde o planejamento até a implementação de políticas públicas, empresariais e de programas e projetos capazes de alavancar o desenvolvimento territorial. A gestão integrada visa a eficácia no alcance das metas; a eficiência na utilização dos recursos e a efetividade das ações. 0 principal fator que impulsiona a gestão é a integração dos vários aspectos que estão diretamente e indiretamente relacionados com o uso dos recursos hídricos e também com a sua proteção ambiental (BRASIL, 2012).

A experiência francesa tem se revelado como importante referência na institucionalização de novas práticas gestoras. No Brasil, esta experiência é a base não apenas da constituição dos novos aparatos gestores estaduais, mas também da própria formulação da Política Nacional de Recursos Hídricos.

A gestão dos recursos hídricos na Europa tem uma diretriz muito recente, adotada em setembro do ano 2000 (QDA - Quadro Diretivo de Água). Havia uma necessidade de um quadro de referência para o conjunto dos problemas da água nos países europeus, já que a gestão dos recursos hídricos era em geral compartimentada. Durante quatro anos, o Conselho Europeu, o Parlamento e a Comissão Européia discutiram a melhor maneira de gerenciamento da água e concluíram que: a partir de 2000, os países deveriam gerenciar a água através de suas bacias hidrográficas. Filosoficamente, é um princípio importante que representou uma mudança na política de gerenciamento. Com essa orientação, a meta era atingir boa qualidade de água num prazo de 15 anos.

A legislação francesa e a brasileira são muito semelhantes nos seus conceitos sobre a gestão dos recursos hídricos. Segundo Little (2006), a definição de "gestão" remete às palavras administrar, gerir ou gerenciar, todavia tais palavras estão mais envolvidas com planos empresariais ou governamentais e também se aplicam a administração de ecossistemas e recursos naturais. Já o termo "territorial" vem da palavra território que é principalmente um conceito político, na realidade é entendido como política específica. A implementação desta gestão se apóia efetivamente, dentre outros instrumentos, no território que se operacionaliza em diferentes escalas.

Na França a gestão dos recursos hídricos ocorre por meio de planos diretores (equivalentes aos nossos planos de bacia hidrográfica) denominados Schémas Directeurs d'Aménagement et de Gestion des Eaux (SDAGE), na escala das grandes bacias hidrográficas e de Schémas d'Aménagement et de Gestion des Eaux (SAGE), na escala das sub-bacias, que contam com o apoio das Commissions Locales de l'Eau (CLE), em português: Comissões Locais da Água. No Brasil, a legislação estabelece que os planos de recursos hídricos devem ser elaborados obedecendo a três escalas: nacional, estadual e de bacia hidrográfica. Falta, na escala dos municípios, um plano que possa dar suporte

BRAGA, L.M.M.; ARGOLLO FERRÃO, A.M. A gestão dos recursos hídricos na França e no Brasil com foco nas bacias hidrográficas e seus sistemas territoriais. Labor \& Engenho, Campinas [SP] Brasil, v.9, n.4, p19-33, out./dez. 2015.

http://www.conpadre.org 
direto ao Plano de Bacia Hidrográfica. Os planos diretores municipais abordam o uso e ocupação do solo, porém não podem ser considerados planos com o foco principal nos recursos hídricos. $\mathrm{Na}$ realidade, em alguns municípios o tema é pouco abordado.

\section{A gestão das águas na França}

A França adequou a média do consumo de água da população a $3.600 \mathrm{~m}^{3} / \mathrm{ano} /$ per capita, sendo que o seu território possui características de clima temperado, altas montanhas, aqüíferos importantes e baixa densidade populacional. No verão, os agricultores são responsáveis por $79 \%$ do consumo de água na França. Depois, vem os usuários de água potável (10\%), os produtores de energia (9\%) e o setor industrial (2\%) segundo dados da France Nature Enviroment (2008).

Quadro 1. Distribuição de água bruta e consumo líquido por categorias de uso.

\begin{tabular}{|c|c|c|c|c|}
\hline uso & energia & água potável & indústria & agricultura \\
\hline $\begin{array}{c}\text { água bruta } \\
\left(34 \text { bilhões de } \mathrm{m}^{3}\right)\end{array}$ & $57 \%$ & $18 \%$ & $10 \%$ & $15 \%$ \\
\hline $\begin{array}{l}\text { consumo líquido } \\
\left(6 \text { bilhões de } \mathrm{m}^{3}\right)\end{array}$ & $22 \%$ & $24 \%$ & $6 \%$ & $48 \%$ \\
\hline
\end{tabular}

Fonte: FRANCE. IFEN, (2008). Disponível em www.fne.asso.fr/.../fne_2008_gestioneaufrance.pdf

A gestão da água na França organiza-se pelas grandes bacias hidrográficas de acordo com a divisão natural seguindo o desenho das bacias, que correspondem aos quatro grandes rios franceses: SeineNormandie, Loire-Bretagne, Adour-Garonne, Rhône-Méditerranée; e ainda, a captação francesa do Reno (bacia Rhin-Meuse), os rios do norte (bacia Artois-Picardie), e a Córsega (Figura 1).

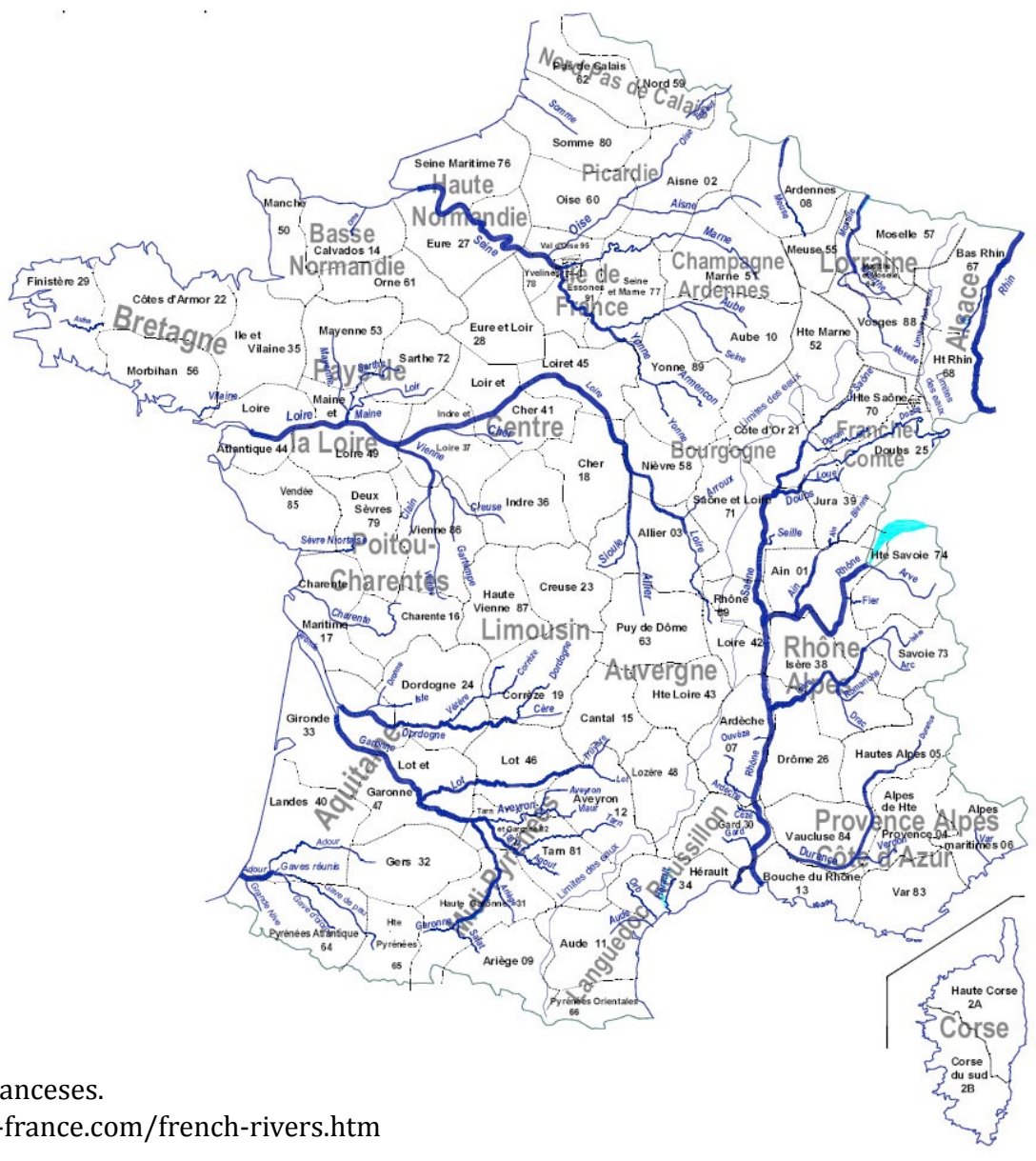

Figura 1. Os quatro grandes rios franceses.
Fonte: Disponível em http://about-france.com/french-rivers.htm

BRAGA, L.M.M.; ARGOLLO FERRÃO, A.M. A gestão dos recursos hídricos na França e no Brasil com foco nas bacias hidrográficas e seus sistemas territoriais. Labor \& Engenho, Campinas [SP] Brasil, v.9, n.4, p19-33, out./dez. 2015. http://www.conpadre.org 
A gestão francesa envolve um grande número de atores como: as diferentes esferas do Governo, pessoas eleitas e representantes de comunidades locais, agentes econômicos, associações e outros. A gestão opera ainda sobre uma multiplicidade de escalas geográficas com regras diferenciadas entre elas como: a Europa (com suas diretrizes), o território nacional, as sete grandes bacias hidrográficas continentais e bacias do exterior, as bacias de encosta próxima ao território nacional, as 22 regiões, os 96 departamentos e as 36.772 comunas francesas. 0 Quadro 2 apresenta os principais rios franceses, seu comprimento, trajeto e a foz de cada um deles.

A Gestão dos Recursos Hídricos na França possui uma longa trajetória que se inicia em 1921 com a Lei Rhône, cujo objetivo principal era a reabilitação do rio Rhône, e que foi substituida pela Lei Grenelle I (primeira fase) em 2007. Existem outros marcos importantes na gestão francesa das águas, como em 1933 quando foi criada a Companhia Nacional do Rhône (sociedade de economia mista) para a geração de energia, navegação e irrigação. Todavia o ano de 1964 marca a principal data para o gerenciamento hídrico francês, quando foi criada a Lei das Águas.

A França vem gerenciando suas águas de forma integrada tendo a bacia hidrográfica como a unidade de medida territorial. Diversos projetos de reforma do direito da água, após a década de 80, insistiam sobre a necessidade de criar planos diretores de água (GAZZANIGA et al.,1998), então em 3 de janeiro de 1992, a Loi Sur l'Eau foi aprovada como nova lei, com destaque para dois parâmetros importantes: o usuário poluidor que deve pagar pela poluição gerada, e a água entendida e declarada como patrimônio da nação francesa. Essa Lei mudou o paradigma francês em relação ao uso da água.

De acordo com a France Nature Enviroment (2008), com a Lei Grenelle I e II atinge-se o ápice de um longo processo de consulta pública para definir o roteiro legislativo do país em termos de ecologia e desenvolvimento sustentável. Na primeira fase da Lei do Meio Ambiente Grenelle abriu-se diálogo com todos os atores da sociedade. De julho a outubro de 2007, realizou-se uma ampla consulta que resultou em 268 compromissos que serviram de base para a lei de planejamento hídrico discutida no Fórum Ambiental Grenelle, a chamada "Grenelle I", promulgada em 3 de agosto de 2009. Ela trata, por meio de 57 itens, sobre medidas que afetam a energia, a construção, transporte, biodiversidade e ambientes naturais, governança, e os riscos ao meio ambiente e à saúde.

A Lei Grenelle I é relativa à execução da chamada "Rodada Grenelle" do meio ambiente, um projeto submetido à votação do Parlamento francês. Já a Lei Grenelle II, de 12 de julho de 2010, trata sobre o empenho nacional pelo meio ambiente e as medidas mais operacionais para exame posterior.

Quadro 2. Principais rios franceses, comprimento, trajeto e foz.

\begin{tabular}{|c|c|c|c|}
\hline Rio & $\begin{array}{l}\text { Comprimento } \\
\text { (em Km) }\end{array}$ & $\begin{array}{l}\text { País ou Estados (Departamentos) } \\
\text { que atravessam }\end{array}$ & Deságue \\
\hline Rhin & 1298 & Suisse, Liechtenstein, Allemagne, Ht-Rhin, Bas-Rhin, Pays-Bas & Mar do Norte \\
\hline Loire & 1012 & $\begin{array}{l}\text { Ardèche, Hte-Loire, Loire, Saône-et-Loire, Allier, Nièvre, Cher, } \\
\text { Loiret, Loir-et-Cher, Indre-et-Loire, Maine-et-Loire, Loire- } \\
\text { Atlantique }\end{array}$ & $\begin{array}{l}\text { Oceano } \\
\text { Atlântico }\end{array}$ \\
\hline Meuse & 950 & Hte-Marne, Vosges, Meuse, Ardennes, Belgique, Pays-Bas & Mar do Norte \\
\hline Rhône & 812 & $\begin{array}{l}\text { Suisse, Ain, Hte-Savoie, Savoie, Isère, Rhône, Loire, Ardèche, } \\
\text { Drôme, Gard, Vaucluse, Bouches-du-Rhône }\end{array}$ & Mar Mediterrâneo \\
\hline Seine & 776 & $\begin{array}{l}\text { Eure, Seine-Maritime, Yvelines, Val-d'Oise, Hauts-de-Seine, Paris, } \\
\text { Val-de-Marne, Essone, Seine-et-Marne, Aube, Côte-d'Or }\end{array}$ & Canal da Mancha \\
\hline Garonne & 647 & $\begin{array}{c}\text { Espagne, Hte-Garonne, Hautes-Pyrénées, Tarn-et-Garonne, Lot- } \\
\text { et-Garonne, Gironde }\end{array}$ & $\begin{array}{l}\text { Oceano } \\
\text { Atlântico }\end{array}$ \\
\hline $\begin{array}{l}\text { Moselle (Afluente } \\
\text { do Rio Rhin) }\end{array}$ & 550 & Vosges, Meurthe-et-Moselle, Moselle, Luxembourg, Allemagne & Rio Rhin \\
\hline
\end{tabular}

BRAGA, L.M.M.; ARGOLLO FERRÃO, A.M. A gestão dos recursos hídricos na França e no Brasil com foco nas bacias hidrográficas e seus sistemas territoriais. Labor \& Engenho, Campinas [SP] Brasil, v.9, n.4, p19-33, out./dez. 2015. http://www.conpadre.org 


\begin{tabular}{|c|c|c|c|}
\hline $\begin{array}{c}\text { Marne (Afluente } \\
\text { do Rio Seine) }\end{array}$ & 525 & Hte-Marne, Marne, Aisne, Seine-et-Marne, Val-de-Marne & Rio Sena \\
\hline $\begin{array}{c}\text { Dordogne } \\
\text { Afluente do } \\
\text { Rio Garonne) }\end{array}$ & 490 & Puy-de-Dôme, Corrèze, Cantal, Lot, Dordogne, Gironde & Rio Garonne \\
\hline $\begin{array}{c}\text { Saône (Afluente } \\
\text { do Rio Rhône) }\end{array}$ & 482 & Vosges, Hte-Saône, Côte-d'Or, Saône-et-Loire, Ain, Rhône & Rio Rhône \\
\hline
\end{tabular}

Fonte: FRANCE (2008). Disponível em www.fne.asso.fr/.../fne_2008_gestioneaufrance.pdf

Os seis grandes projetos da Lei Grenelle II são:

- melhorias de eficiência de energia e harmonização de ferramentas de planejamento;

- organização dos transportes ambientalmente mais amigáveis ao fornecer as necessidades de mobilidade;

- redução do consumo de energia e da produção de carbono;

- preservação da biodiversidade;

- controle de risco, tratamento de resíduos e manutenção da saúde; implementação da nova governança e base ecológica de consumo e de produção mais sustentável.

De acordo com a France Nature Enviroment (2008), para cada uma das sete bacias hidrográficas francesas, a Lei das Águas de 1964 criou as Agências de Águas e os Comitês de Bacia Hidrográfica. Segundo a Lei das Águas em seu Art. 13, no nível de cada bacia ou grupo de bacias deve ser criado um comitê composto em partes iguais por:

- representantes de diferentes categorias de usuários e pessoas competentes;

- representantes designados pelas comunidades locais;

- representantes administrativos.

Esta organização - comitê de bacia - deve ser consultada sobre a adequação do trabalho e o desenvolvimento de interesses comuns na área sob sua jurisdição, bem como sobre lit́gios entre comunidades ou grupos interessados e, mais genericamente, sobre todos os assuntos que abrangem a lei.

O Art. 14. prevê a criação, no nível de cada bacia, de uma agência financiadora da bacia, uma instituição de administração pública com personalidade jurídica e autonomia financeira, responsável por facilitar as diversas ações de interesse da bacia. Cada agência é regida por um conselho formado por representantes de autoridades competentes no domínio da água, representantes dos governos locais e de diferentes categorias de usuários, em proporção equitativa.

Portanto, com a Lei das Águas na França criaram-se as Agências de Água e os Comitês de Bacia. É de responsabilidade das Agências de Água o SDAGE (Plano Diretor de Bacias e Gestão de Água), o SAGE (Ordenamento Territorial e Gestão de Água), e os CLE (Comissões Locais da Água). Os Comitês de Bacia interagem com o SDAGE e com o SAGE. Em francês a palavra cle significa "chave", e não é atoa que o CLE tem um papel-chave no sentido de encontrar solução para a maioria dos problemas de governança das águas na França. 0 esquema da Figura 2 mostra as relações entre os organismos que regulam a água na França.

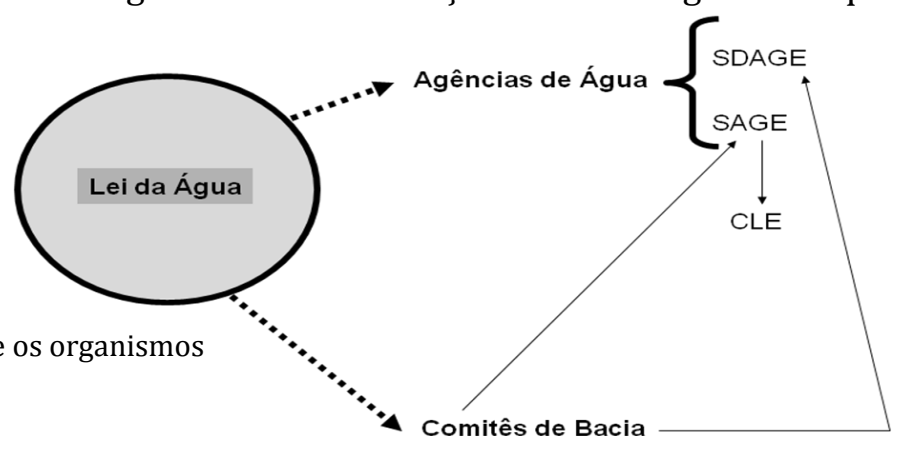

Figura 2. Esquema simplificado das relações entre os organismos que regulam a água na França.

Montado por Luci Braga.

BRAGA, L.M.M.; ARGOLLO FERRÃO, A.M. A gestão dos recursos hídricos na França e no Brasil com foco nas bacias hidrográficas e seus sistemas territoriais. Labor \& Engenho, Campinas [SP] Brasil, v.9, n.4, p19-33, out./dez. 2015. http://www.conpadre.org 
De acordo com a France Nature Enviroment (2008), as Agências de Água são os órgãos executivos responsáveis pela implementação da política desenvolvida pelos Comitês de Bacia. Constituem-se como instituição pública dotada de personalidade jurídica e autonomia financeira, com um diretor nomeado pelo governo, sob a supervisão conjunta do Ministério da Ecologia, Planejamento e Desenvolvimento Sustentável (que regula a qualidade da água potável), e do Ministério da Economia, Finanças e Indústria (que regula o nível das tarifas de água).

Trata-se de um sistema regulado pelo governo central (de grandes diretrizes) supervisionado no âmbito das Regiões Hidrográficas pelos Organismos de Bacia, que são os Comitês Colegiados auxiliados técnica e financeiramente pelas Agências da Água, e descentralizado pela atuação das regiões, departamentos e comunas, que executam as ações de interesse local, diretamente ou por contrato.

Existe, assim, um importante conjunto de elementos inter-atuantes nas bacias hidrográficas francesas, tais como: a Comissão Interministerial do Meio Ambiente, Agências de Água, Comitês de Bacia, Comitês Técnicos de Água e Coletividades Locais.

- Comissão Interministerial do Meio Ambiente define as questões relativas a água e ao meio ambiente de maneira integrada. Cabe aos Ministérios de Saúde Pública, Indústria, Equipamentos, Agricultura, Interior, Meio Ambiente, Economia e Finanças;

- Agências de Água possuem a missão de viabilizar o aporte de financiamento aos empreendedores públicos e privados que pretendem executar obras e estudos de interesse comum na bacia;

- Comitês de Bacia representam o "Parlamento das Águas", consultados sobre as principais alternativas da política dos recursos hídricos na bacia;

- Comitês Técnicos de Água fazem os estudos do potencial hídrico;

- Coletividades Locais são organizadas em comunas (ou municípios), regiões e departamentos. Participam das deliberações dos organismos de bacia.

\subsection{Agências de Água}

Na França, as seis Agências de Água têm contratos de desempenho com o Ministério do Desenvolvimento Sustentável. Empregam cerca de 1.800 funcionários com foco em proteger os recursos hídricos e os ambientes aquáticos, bem como reduzir a poluição proveniente de fontes diversas. As estratégias que contribuem para a implementação de instrumentos econômicos na bacia são:

- Agências de Água são os produtores e gestores de dados e monitoramento de redes de água, da qualidade das águas naturais ao lado do ONEMA - órgão responsável pela condução e implementação do sistema nacional informação sobre água (assim como o Sistema Nacional de Informações sobre Recursos Hídricos - SNIRH - brasileiro);

- Comunicar e favorecer a participação do cidadão;

- Participar de atividades internacionais com os países que fazem fronteira (comissões internacionais) e implementar ações humanitárias (Lei "Oudin-Santini" de 2005).

Segundo o Quadro Diretivo de Água de Outubro de 2000, as Agências de Água são atores-chave na implementação da política pública da água na França, e são organizadas em torno do princípio da gestão integrada das bacias hidrográficas; cabe a elas executar suas missões no âmbito dos programas plurianuais com suas ações principais voltadas a criar o bom estado das águas.

As atividades das Agências de Água são planejadas para vários anos e estão sujeitas a aprovação pelos respectivos Comitês de Bacia e Conselho Administrativo; e ainda, pelo Primeiro-Ministro. Cada agência cobra as taxas de água cabíveis, que são pagas por todos os usuários de água, obedecendo o princípio do poluidor-usuário-pagador. As agências redistribuem o valor da cobrança em forma de subvenções para as autoridades locais, industriais e agricultores. Financiam projetos específicos de interesse coletivo de controle de poluição, saneamento e gestão. Outras ações importantes advindas do valor da cobrança acontecem em relação às águas superficiais, subterrâneas e águas do território marítimo. 


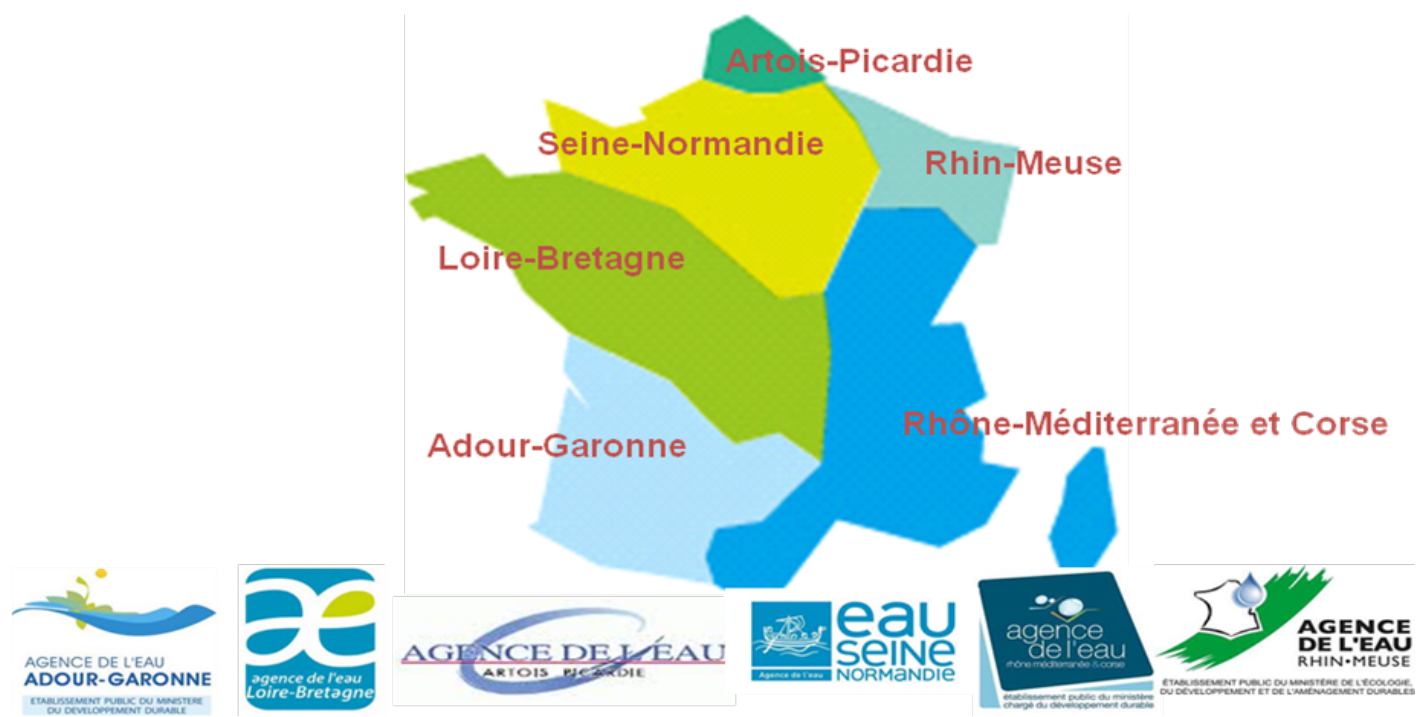

Figura 3. Mapa das Bacias Hidrográficas Francesas, as agências de água e os respectivos logotipos. Montado por Luci Braga.

Conforme a France Nature Enviroment (2008), as Agências de Água alavancam a gestão sustentável da água com instrumentos econômicos (taxas e subsídios) e receitas fiscais ambientais coletadas dos usuários (consumidores e empresas) obedecendo os princípios da precaução e da compensação por danos ao ambiente reunidos sob o título de "Bacia de Solidariedade". Todavia, a maior parte dos royalties vem através da conta de água dos consumidores residenciais. Nos últimos anos os objetivos gerais das Agências de Água para atingir o bom estado das águas estabelecem as seguintes prioridades:

- redução das emissões de poluentes de todas as fontes;

- prevenir a qualidade da água fornecida;

- desenvolvimento sustentável das atividades econômicas que dependem de água;

- a preservação e restauração dos ecossistemas aquáticos e zonas úmidas;

- controle de cheias (áreas de expansão de inundação natural, a manutenção dos rios);

- solidariedade urbana - saneamento rural de esgoto e água potável;

- solidariedade humanitária e cooperação internacional;

- informação, sensibilização pública, educação para a gestão sustentável, conservação da água e ambientes aquáticos.

As Agências de Água fazem a verificação dos resultados (do bom estado da água) e ajudam a promover a otimização ambiental de suas intervenções. Avaliam a eficácia e selecionam os projetos em ambientes aquáticos, com ênfase na ação preventiva e que trabalhem conjuntamente com ação regulamentar (polícia da água) e com ação local e territorial (através de contratação). Na Figura 4, a divisão de ajuda financeira às Agências de Água (em \%) dentro do $9^{\circ}$ Quadro do Programa de Intervenção 2007-2012.

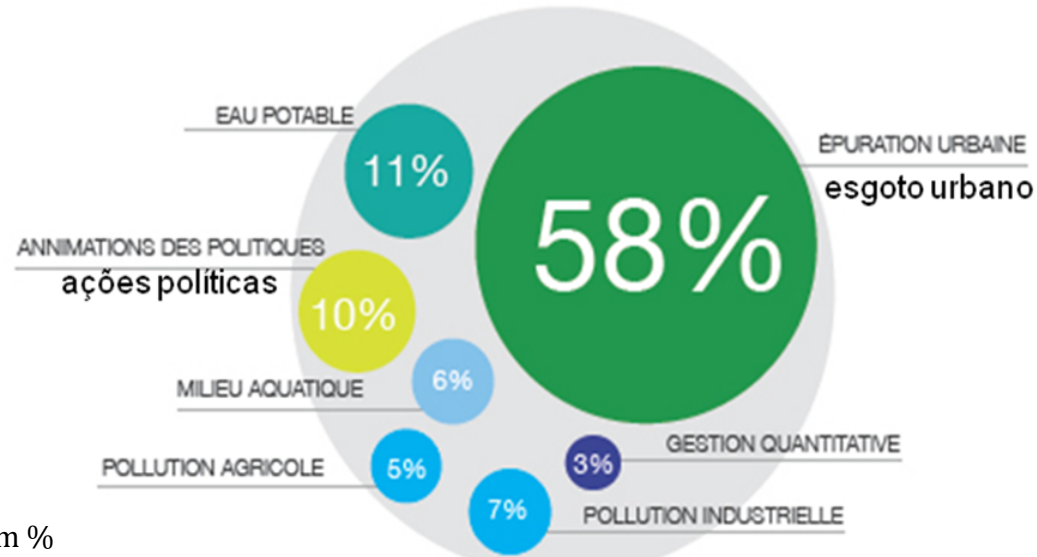

Figura 4. Valor da Água (na França), em \%

Fonte: FRANCE. IFEN, (2008). Disponível em www.fne.asso.fr/.../fne_2008_gestioneaufrance.pdf 


\subsection{Comitês de Bacia}

Após 40 anos, os Comitês de Bacia e as Agências de Água garantem o secretariado e a boa atuação perante a população. Os Comitês de Bacia são órgãos deliberativos, que reúnem todas as partes interessadas (autoridades locais, indústria, agricultores, estados, ONGs, consumidores) em cada uma das sete principais bacias da França. São responsáveis pela democracia da água e pelo desenvolvimento participativo. Estabelecem a estratégia correta em relação a água e aos meios aquáticos na bacia (SDAGE). Votam o programa das Agência de Água em cada bacia hidrográfica e as taxa de imposição, dentro do limite das taxas e dentro do máximo fixado por lei. Depende do tamanho da bacia o número de representantes, que varia de 36 membros na Bacia da Córsega para 190 membros na Bacia do Loire-Bretanhe. Existe uma organização semelhante para as bacias além mar, ou seja fora do território francês europeu. São os Comitês de Bacia e Escritórios de Água. Sua composição se divide em:

- funcionários eleitos, incluindo representantes dos conselhos gerais e regionais e, principalmente, dos municípios ou suas associações com experiência no setor hídrico;

- os representantes dos usuários de água e ambientes aquáticos, as organizações sócioprofissionais, associações de proteção ambiental aprovadas, órgãos de defesa do consumidor, da pesca, e pessoas qualificadas;

- representantes do Estado ou de suas instituições públicas.

A tarefa dos Comitês de Bacia é prestar assessoria e desenvolver uma política coerente na bacia, afinada com as diretrizes nacionais e européias. Os presidentes são eleitos entre os membros de cada Comitê de Bacia. Comissões são estabelecidas como grupos de trabalho sobre questões específicas (assim como as câmaras técnicas nos comitês brasileiros). Existem comissões geográficas e comissões temáticas. 0 esquema da Figura 5 ilustra os objetivos de um comitê de bacia francês e sua composição.

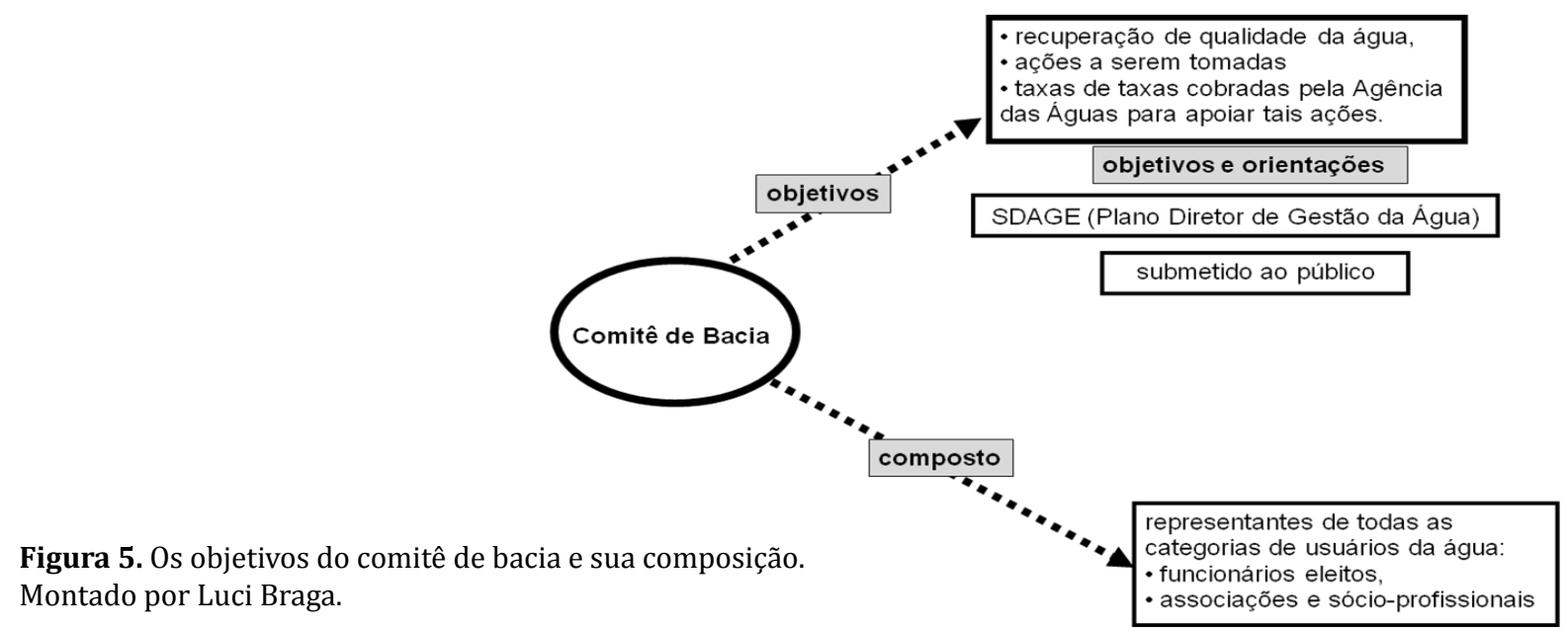

O planejamento previsto pelo Código Ambiental estabelece as funções do SDAGE e do SAGE. O SDAGE fixa as orientações fundamentais de uma gestão equilibrada em recursos hídricos que será elaborada, adotada e revisada pelo Comitê de Bacia e aprovada pelo prefeito coordenador da Bacia. 0 objetivo do SDAGE é assegurar a harmonia do plano e incluir o SAGE no seu campo de competência. O SAGE desenvolve um Relatório de Compatibilidade e fixa os objetivos gerais do valor - mise en valeur - e da proteção da qualidade e quantidade dos recursos hídricos. O SAGE é elaborado e revisado pela Comissão Local de Água (CLE) e aprovada pelo prefeito coordenador da bacia; portanto, a visão do uso e ocupação do solo e da água na escala do município é abordada e respeitada.

\section{A gestão das águas no Brasil}

O Código das Águas - Decreto 24.643 de 1934 - foi o primeiro passo rumo à ideia de controle sobre a água como um bem de todos, conforme a sequência de marcos apresentada no Quadro 3. De fato, a gestão dos recursos hídricos no Brasil apresenta conflitos, entraves e peculiaridades que remetem aos primeiros passos dados no País, desde a construção da pioneira Usina Hidrelétrica de Marmelos

BRAGA, L.M.M.; ARGOLLO FERRÃO, A.M. A gestão dos recursos hídricos na França e no Brasil com foco nas bacias hidrográficas e seus sistemas territoriais. Labor \& Engenho, Campinas [SP] Brasil, v.9, n.4, p19-33, out./dez. 2015.

http://www.conpadre.org 
em $1889^{1}$ até meados da década de 1970, período em que a geração de energia hidrelétrica foi o foco da gestão dos recursos hídricos.

Quadro 3. Marcos da Gestão das Águas no Brasil.

\begin{tabular}{|c|l|}
\hline Ano & Evolução Histórica \\
\hline 1934 & $\begin{array}{l}\text { Código das Águas - Decreto 24.643 - atribuição de gestão ao Ministério da Agricultura - dificuldades: com } \\
\text { exceção das águas públicas comuns, todas as nascentes e águas localizadas em terrenos particulares eram } \\
\text { consideradas de domínio privado. }\end{array}$ \\
\hline 1960 & $\begin{array}{l}\text { A atribuição de gestão passa para o Ministério de Minas e Energia (o setor torna-se um dos principais } \\
\text { usuários de recursos hídricos). }\end{array}$ \\
\hline 1980 & $\begin{array}{l}\text { O Poder Executivo elabora uma proposta para constituir um Sistema Nacional de Gerenciamento dos } \\
\text { Recursos Hídricos - discussão de uma legislação específica para o setor. }\end{array}$ \\
\hline 1981 & $\begin{array}{l}\text { Lei } 6.938 \text { - Política Nacional de Meio Ambiente - diretrizes e definições inovadores para a gestão } \\
\text { ambiental no país. } \\
\text { Constituição Federal do Brasil - As águas são agora de domínio público (Bem da União, rios localizados em } \\
\text { mais de um estado; Bem dos estados, todos os outros rios). União, estados e municípios são entes federados. } \\
\text { A União passa a legislar sobre os recursos hídricos e o suplementar passa a ser dos estados. Acompanhar e } \\
\text { fiscalizar são obrigações comuns entre União, estados e municípios. }\end{array}$ \\
\hline 1991 & $\begin{array}{l}\text { São Paulo foi pioneiro a implementar os próprios sistemas de gestão de recursos hídricos. } \\
\text { Conferência Internacional de Água e Meio Ambiente (ICWE) em Dublin [Irlanda], preparatória para a Rio-92. } \\
\text { Princípios definidos para a gestão integrada preferencialmente baseada nas bacias hidrográficas. }\end{array}$ \\
\hline 1995 & $\begin{array}{l}\text { No âmbito do Ministério do Meio Ambiente foi criada a Secretaria de Recursos Hídricos. } \\
\text { Lei das Águas - Lei Federal 9.433 - novo marco no desenvolvimento da gestão de recursos hídricos no país. }\end{array}$ \\
\hline 1997
\end{tabular}

Fonte: Baseado em TUCCI (2004). Desenvolvimento dos Recursos Hídricos no Brasil. Adaptado por Luci Braga.

Os antecedentes da legislação sobre o processo de institucionalização dos sistemas de recursos hídricos culminam com a edição da Lei no 9.433/97 (Lei das Águas), instituída a partir das diretrizes traçadas pela Política Nacional de Recursos Hídricos, em concordância com as discussões geradas em diversas conferências internacionais sobre o tema. Destacam-se os objetivos estabelecidos quanto à administração dos recursos hídricos no Brasil, com foco na gestão participativa da água e a organização dos comitês de bacias hidrográficas como unidade principal de atuação da sociedade e do poder público em conjunto, transformando-se num marco da gestão ambiental para assegurar a disponibilidade de água para a atual e as futuras gerações.

\subsection{O Plano de Recursos Hídricos}

O planejamento na gestão das águas é um processo que procura definir as melhores alternativas de utilização dos recursos hídricos e assim orientar as tomadas de decisão. A Política Nacional de Recursos Hídricos (Lei 9.433/97) ressalta que a consolidação da gestão participativa exige um processo sistemático de educação e cooperação entre agentes e atores - públicos e privados - , bem como o empreendimento de esforços visando a formação de pessoal para a participação nos entes colegiados do sistema, incluindo a formação de novos perfis profissionais e a consequente adequação dos currículos (BRASIL, 2006, p.135).

Embora caiba a cada esfera administrativa um papel específico na gestão de recursos hídricos, há uma inter-relação entre os planos nacional, estaduais e de bacias. De acordo com a Figura 6, as articulações e a integração entre os Planos de Recursos Hídricos, em suas diferentes escalas,

\footnotetext{
1889 - Início da operação da primeira usina hidrelétrica do continente. A Usina de Marmelos foi idealizada pelo industrial mineiro Bernardo Mascarenhas, em Juiz de Fora [MG].
}

BRAGA, L.M.M.; ARGOLLO FERRÃO, A.M. A gestão dos recursos hídricos na França e no Brasil com foco nas bacias hidrográficas e seus sistemas territoriais. Labor \& Engenho, Campinas [SP] Brasil, v.9, n.4, p19-33, out./dez. 2015. http://www.conpadre.org 
devem ser efetuadas a partir de um constante diálogo e do compartilhamento de informações entre as entidades que compõem o SINGREH (Sistema Nacional de Gerenciamento de Recursos Hídricos): conselhos, comitês de bacia, órgãos gestores e agências.

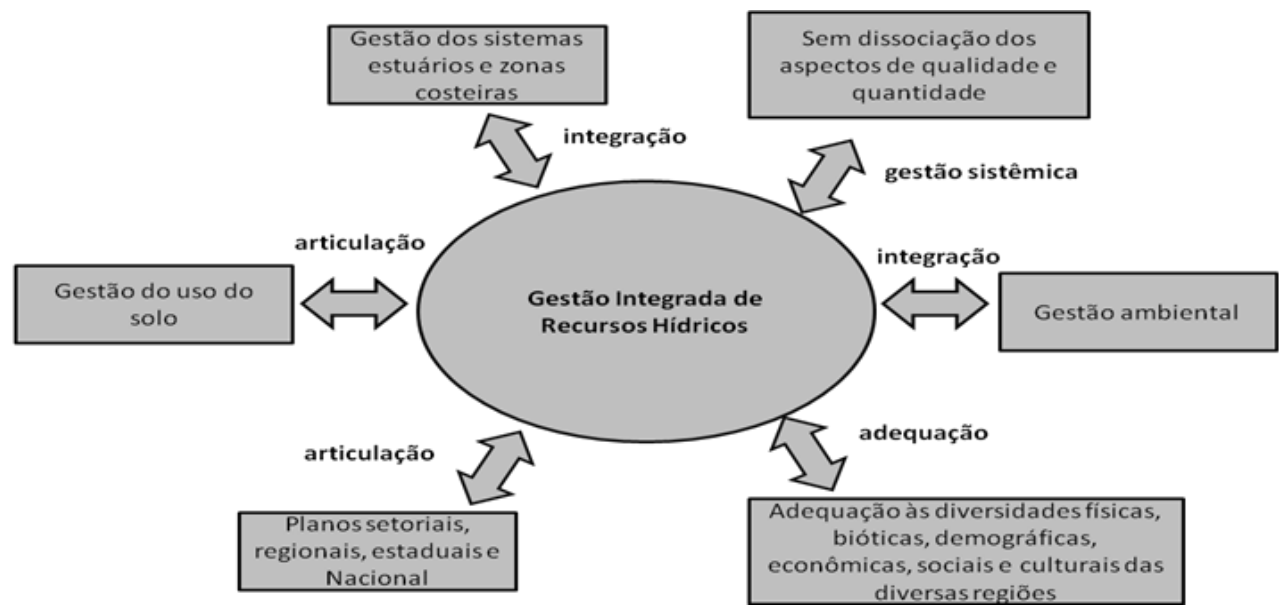

Figura 6. Gestão integrada de recursos hídricos e possíveis interações. Fonte: Cadernos de Capacitação de Recursos Hídricos. CEDOC, 2011, p.13.

Esse tipo de planejamento consiste na busca de soluções de compromisso, principalmente com o objetivo de minimizar conflitos pelo uso da água, que podem surgir a partir de múltiplos interesses, existentes ou potenciais, do poder público ou da sociedade organizada. É importante considerar as metas de cunho econômico, financeiro, social, cultural ou ambiental, para minimizar conflitos ou mesmo propiciar a prevenção e a mitigação de eventos hidrológicos críticos, como as secas ou inundações.

A Lei das Águas prevê instrumentos da Política Nacional de Recursos Hídricos, como: planos de recursos hídricos; enquadramento dos corpos de água em classes segundo os usos preponderantes; outorga de direitos de uso de recursos hídricos; cobrança pelo uso de recursos hídricos; e um sistema de informação sobre recursos hídricos. Os planos e o enquadramento devem ser elaborados levando-se em conta os interesses sociais, econômicos, políticos e ambientais que devem ser negociados e compromissados nos comitês de bacia e nos conselhos de recursos hídricos.

As bases técnicas visam mostrar as potencialidades e as perspectivas do crescimento das demandas hídricas, os níveis de comprometimento, as restrições de uso e as questões institucionais, legais e jurídicas da água (BRASIL, 2011, p. 20).

A Figura 7 apresenta esquematicamente a Matriz institucional do SINGREH — Sistema Nacional de Gerenciamento de Recursos Hídricos.

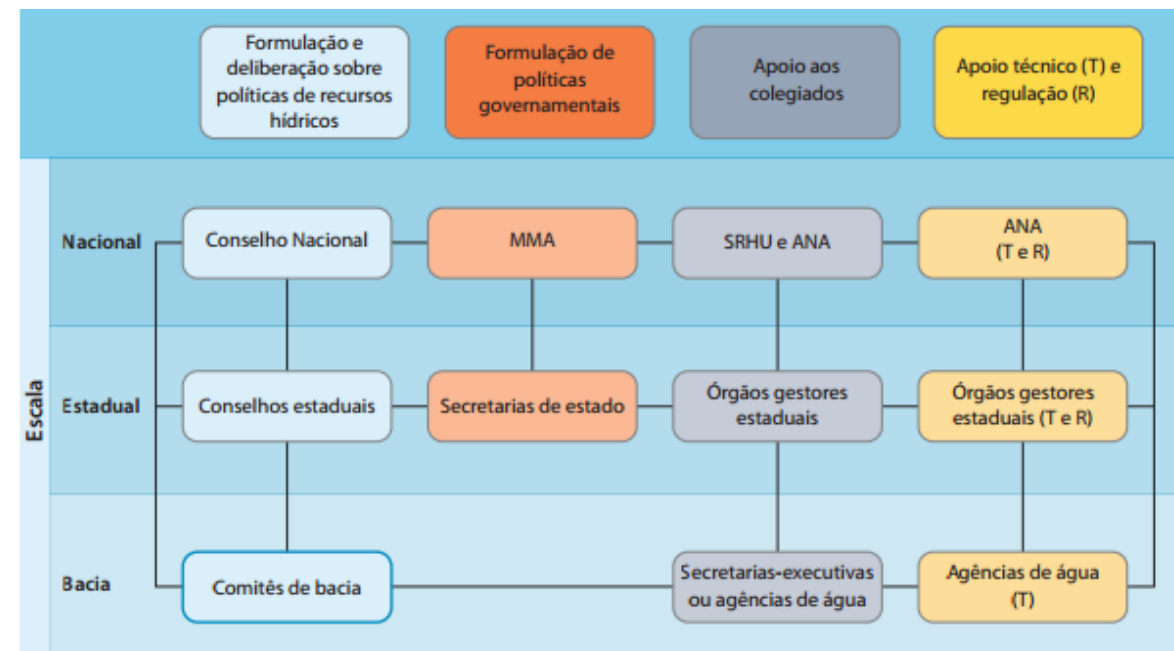

Figura 7. Matriz

institucional do Sistema Nacional de Gerenciamento de Recursos Hídricos.

Fonte: Cadernos de Capacitação de Recursos Hídricos. CEDOC, 2011, p.13.

BRAGA, L.M.M.; ARGOLLO FERRÃO, A.M. A gestão dos recursos hídricos na França e no Brasil com foco nas bacias hidrográficas e seus sistemas territoriais. Labor \& Engenho, Campinas [SP] Brasil, v.9, n.4, p19-33, out./dez. 2015. http://www.conpadre.org 
O processo de planejamento deve ser orientado por três situações: situação atual dos recursos hídricos, situação desejada e situação possível. Os Planos de Recursos Hídricos trabalham com horizontes de 10 a 20 anos, com revisões periódicas. Os objetivos são: definição de uma agenda de recursos hídricos, identificação de ações e gestão, programas, projetos, obras e investimentos prioritários.

\subsection{Os órgãos da gestão e suas atribuições}

\subsubsection{Conselho Nacional de Recursos Hídricos - CNRH}

O Conselho Nacional de Recursos Hídricos - CNRH - promove a articulação do planejamento nacional, regional, estaduais e dos setores usuários, a fim de elaborar a Política de Recursos Hídricos. Aprova os mecanismos e valores da cobrança. Desenvolve atividades desde junho de 1998, ocupando a instância mais alta na hierarquia do Sistema Nacional de Gerenciamento de Recursos Hídricos (instituído pela Lei no 9.433, de 8 de janeiro de 1997). É um órgão colegiado, que desenvolve e institui regras e metodologias de mediação entre os diversos usuários da água, motivo pelo qual, revela-se um dos grandes responsáveis pela implementação da gestão dos recursos hídricos no País. Por articular a integração das políticas públicas no Brasil é reconhecido pela sociedade como orientador para um diálogo transparente no processo de decisões no campo da legislação de recursos hídricos.

\subsubsection{Secretaria de Recursos Hídricos e Ambiente Urbano - SRHU}

A Secretaria de Recursos Hídricos e Ambiente Urbano - SRHU - exerce as funções de Secretaria Executiva do CNRH.

\subsubsection{Agência Nacional das Águas - ANA}

A Agência Nacional de Águas - ANA - implementa a Política de Recursos Hídricos, através dos Instrumentos de Gestão. Efetua a cobrança pelo uso da água em rios de domínio da União.

\subsubsection{Agência de Bacias}

A Agência de Bacias - (ou Entidade Delegatária) - elabora o Plano de Bacia; gerencia os recursos da cobrança pelo uso da água; etc. As agências de bacias hidrográficas são unidades executivas descentralizadas de apoio aos seus respectivos Comitês de Bacia Hidrográfica, destinadas a prestarlhes suporte administrativo, técnico e econômico. Também são responsáveis por administrar os recursos oriundos da cobrança pelo uso da água que lhes são repassados, bem como, pela divisão dos mesmos para que sejam investidos em projetos que atendam ao plano de bacia definido pelo Comitê.

\subsubsection{Conselhos Estaduais de Recursos Hídricos}

Os Conselhos Estaduais de Recursos Hídricos conduzem a Política Estadual no âmbito dos respectivos estados.

\subsubsection{Comitê de Bacia Hidrográfica - $\mathrm{CBH}$}

Os Comitês de Bacia Hidrográfica - CBH - elaboram, aprovam e acompanham a execução dos Planos de Bacia; estabelecem mecanismos e valores para a cobrança pelo uso da água. Possuem uma composição tripartite: Poder Executivo (União, Estados e Municípios) com $40 \%$ de representação; usuários de água, com 40\%; e a sociedade civil, com 20\%. Portanto, os Comitês de Bacia Hidrográfica constituem-se em órgãos colegiados da gestão de recursos hídricos, com atribuições de caráter normativo, consultivo e deliberativo, integrantes do Sistema Nacional de Gerenciamento de Recursos Hídricos. Os Comitês devem integrar as ações do Governo em suas diferentes esferas, seja no âmbito dos Municípios, dos Estados ou da União. Possuem como objetivo respeitar e defender os diversos ecossistemas naturais, promover a conservação e recuperação dos corpos d'água, e garantir a utilização racional e sustentável dos recursos hídricos. 


\subsubsection{Consórcio Intermunicipal}

Considera-se Consórcio Intermunicipal, a associação de Municípios, integrantes de mesmo aglomerado urbano ou microrregional. A participação dos Municípios nos Consórcios ocorre mediante expressa autorização legal, a partir da apresentação de proposta pelo Prefeito que deve posteriormente ser aprovada pela Câmara de Vereadores. Essa associação tem como finalidade proporcionar a execução de serviços públicos de interesse comum ou obras, adquirir bens, produtos e equipamentos, bem como, a realização de eventos no âmbito da competência e atribuição municipal. Os Consórcios Intermunicipais possuem Plano de Atuação (anual ou bienal), devidamente definido e aprovado pela sua diretoria (composta por representantes dos Municípios participantes), contemplando todas as ações concretas a serem realizadas no referido período.

\subsubsection{Agência de Regulação}

As Agências de Regulação constituem-se em Pessoas Jurídicas de Direito público interno, geralmente sob a forma de autarquia especial ou outro ente da administração indireta. As agências reguladoras foram criadas para fiscalizar a prestação de serviços públicos praticados pela iniciativa privada. Além de controlar a qualidade na prestação do serviço, estabelecem regras para o referido setor. São exemplos de agências de regulação atualmente existentes no Brasil, a Agência Nacional de Águas (ANA), a Agência Nacional de Energia Elétrica (ANEEL), a Agência Nacional de Telecomunicações (ANATEL), Agência Nacional de Saúde Suplementar (ANS), Agência Nacional de Vigilância Sanitária (ANVISA), entre outras.

\subsubsection{Redes de Organismos de Bacias}

Tratam-se de redes que integram organismos de bacias (Comitês, Agências e Consórcios) nacionais ou internacionais. Têm por objetivo proporcionar o intercâmbio de experiências e conhecimento no intuito de promover de forma participativa e descentralizada a gestão de recursos hídricos em prol do interesse coletivo de toda a sociedade. São exemplos: a Rede Brasil de Organismos de Bacias (REBOB), Rede Latino Americana de Organismos de Bacias (RELOB) e a (RIOB) Rede Internacional de Organismos de Bacias (SÃO PAULO, 2014).

\section{Comitê da Bacia PCJ, o primeiro a surgir no Brasil}

A Bacia PCJ é formada pelos rios Piracicaba, Capivari e Jundiaí. Nesta bacia se localizam as principais represas do Sistema Cantareira, que desde 2012 vem atravessando uma grave crise hídrica, tendo atingido em 2014 índices que decretaram a pior seca de sua história, fechando o ano de 2015 com uma situação um pouco mais amena porém ainda crítica. 0 seu território [...]

[...] abrange áreas de 76 municípios dos quais 62 têm sede nas áreas de drenagem da região. Desses, 58 estão no Estado de São Paulo e 4 em Minas Gerais. Dos municípios que têm território na região PCJ e sede em outras bacias, 13 estão em São Paulo e 1 em Minas Gerais.

[...] Com aproximadamente 5 milhões de habitantes, a região é considerada uma das mais importantes do Brasil devido ao seu desenvolvimento econômico, que representa cerca de 7\% do Produto Interno Bruto (PIB) Nacional. As taxas geométricas de crescimento previstas para as populações urbanas da região, são decrescentes, passando de 2,09\% a.a., no período 2000/2005, para 1,19\% a.a., no período 2015/2020 [...] (PLANO DE BACIAS PCJ 2004-2007).

Por ser o território de uma região com grande concentração urbana e industrial, a Unidade Hidrográfica de Gerenciamento de Recursos Hídricos - UGRHI-5 - correspondente à porção paulista da Bacia PCJ (Figura 8) vem apresentando sérios problemas de degradação dos recursos hídricos em parte devido aos numerosos conflitos pelo uso da água, agravados a cada ano desde a implantação da transposição de águas para a Bacia do Alto Tietê através do Sistema Cantareira, mas também devido à falta de uma gestão integrada dessas bacias hidrográficas, particularmente no que se refere ao uso e ocupação do solo, o que deixa claro a extrema necessidade de um plano de ordenamento territorial integrado ao planejamento das bacias hidrográficas do PCJ e do Alto Tietê.

BRAGA, L.M.M.; ARGOLLO FERRÃO, A.M. A gestão dos recursos hídricos na França e no Brasil com foco nas bacias hidrográficas e seus sistemas territoriais. Labor \& Engenho, Campinas [SP] Brasil, v.9, n.4, p19-33, out./dez. 2015.

http://www.conpadre.org 


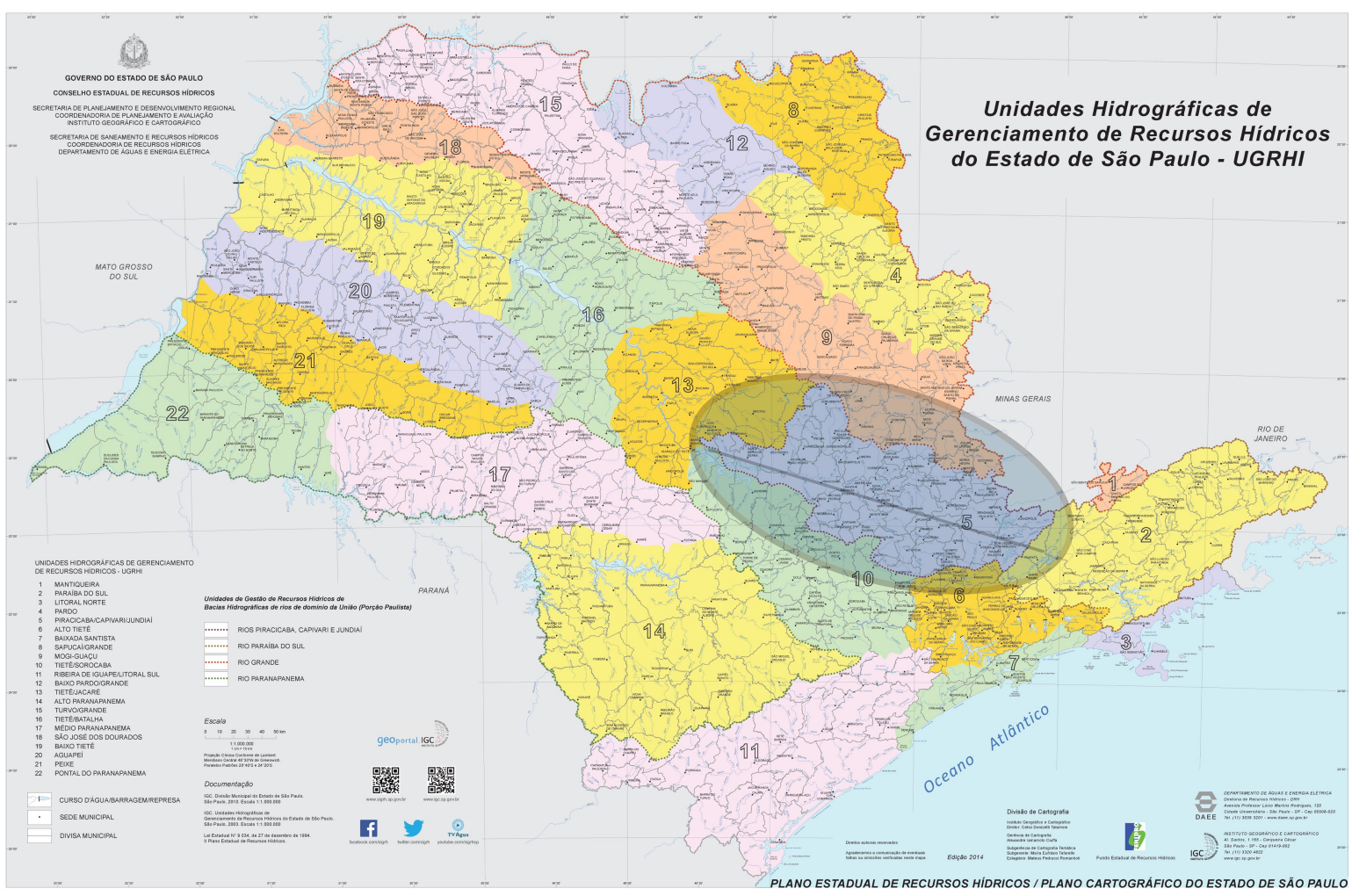

Figura 8. Unidades Hidrográficas de Gerenciamento de Recursos Hídricos do Estado de São Paulo — UGRHI, com destaque para a UGRHI-5 (porção paulista da Bacia PCJ), adaptação dos Autores. Fonte: SÃO PAULO / IGC. Disponível em: http://www.igc.sp.gov.br/produtos/ugrhi.html

O reconhecimento da água como um recurso limitado conduziu à criação de novas políticas, à reformulação de legislações e à reestruturação institucional, cuja principal conseqüência foi a criação, em 1991, da Política Estadual de Recursos Hídricos do Estado de São Paulo.

\subsection{Comitê de Bacia PCJ}

O Comitê de Bacia PCJ é um órgão colegiado composto por representantes do Poder Executivo (federal, estadual e municipal), de usuários de água e da sociedade civil. É deliberativo e funciona como um "Parlamento das Águas". Sua criação está prevista em leis federal e estaduais. Seu objetivo é fazer a gestão dos recursos hídricos tendo a bacia hidrográfica como foco, de forma descentralizada e participativa. Não possui personalidade jurídica, podendo contar com apoio técnico e financeiro de outros órgãos.

\subsection{Agência de Água PCJ}

Entidade criada no âmbito do Comitê de Bacia PCJ para atuar como sua Secretaria Executiva. É responsável pelo gerenciamento dos recursos financeiros oriundos da cobrança pelo uso dos recursos hídricos. Sua natureza jurídica não está definida no âmbito federal. Em São Paulo a legislação prevê a figura de Fundação de Direito Privado. Foi inaugurada em 16 de dezembro de 2005.

\subsection{Consórcio Intermunicipal PCJ}

Associação entre prefeituras e empresas com objetivo de organizar e desenvolver projetos, serviços e ações de interesse comum. Possui personalidade jurídica, neste caso na forma de associação civil de direito privado, sem fins lucrativos. Seus associados contribuem financeiramente para o custeio da entidade e no implemento de atividades e ações previstas em seu Plano de Atuação. Os Consórcios e as Associações Intermunicipais de Bacia Hidrográfica podem receber delegação para exercer funções de Agência de Água, por período determinado, a critério e convite do Comitê de Bacia. 


\section{Conclusão}

No Brasil a gestão das águas ainda carece de uma melhor organização, dado o reduzido número de comitês de bacia bem estruturados e a dificuldade na instituição da cobrança da água. Observa-se que na gestão francesa são essas, justamente, as características que permitem otimizar a administração. Portanto, há que se buscar mecanismos de adaptação à cultura vigente no Brasil, para que os comitês possam se organizar tecnicamente com maior agilidade devido à urgência que o tema gestão das águas exige. Contudo, para que isso ocorra, também é necessário que o apoio político seja consistente, no sentido de promover as condições essenciais para que os comitês sigam conquistando autonomia e representatividade de todos os setores da sociedade.

Confrontando o modelo de gestão de recursos hídricos na França e no Brasil é possível perceber que a principal diferença reside na esfera municipal, a qual, na França é muito mais participativa e atuante no âmbito das bacias e microbacias correspondentes. Isso se dá tanto pelas diferentes características territoriais desses dois países, como pela heterogeneidade cultural no que tange à postura do povo com relação à participação política.

No Brasil, a origem da criação dos comitês também é fator que merece destaque. Nota-se uma marcante diferença entre os que surgiram por iniciativa da sociedade civil organizada e posteriormente receberam apoio do governo, como foi o caso do Comitê da Bacia PCJ. Por outro lado, os comitês criados pelo Estado e posteriormente apresentados à sociedade, ainda se encontram em estágio de estruturação ou, em muitos casos, nem sequer saíram do papel. A participação da sociedade nos comitês mais organizados tem se mostrado efetiva e os resultados têm sido positivos.

No Brasil, a urbanização acelerada e em geral sem planejamento adequado não vem acompanhada dos investimentos necessários em infraestrutura para os sistemas hídricos e territoriais, especialmente os relacionados a saneamento. As periferias das regiões metropolitanas e das grandes aglomerações urbanas brasileiras apresentam grande carência de sistemas de abastecimento de água e de coleta e tratamento de esgoto. Todavia, nas regiões Sul, Sudeste e Nordeste, essa urbanização ocupou boa parte das principais bacias hidrográficas, gerando conflito entre os grandes usuários de água, como é o caso dos setores de energia hidrelétrica e de saneamento. Os municípios guardam uma forte relação de interdependência quando se trata de compartilhar os recursos hídricos, por isso, uma atuação integrada dos governos municipais no contexto de uma mesma bacia hidrográfica otimizaria o processo decisório quanto aos investimentos em infraestrutura dos sistemas hídricos e territoriais de interesse comum.

O caso francês prova que uma gestão democrática na bacia só será possível se existir:

- identificação e coordenação dos atores responsáveis pela gestão das águas;

- a criação de órgãos consultivos que promovam uma "democracia da água", associada a um processo de sensibilização e difusão da informação confiável;

- implementação de uma cultura ampla, consciente, de solidariedade no que se refere aos recursos hídricos, bem como, de solidariedade financeira através da cobrança pelo princípio do "usuário poluidor-pagador";

- desenvolvimento de um planejamento com metas de médio e longo prazos, dividido em programas plurianuais;

- a médio prazo, a necessidade de foco permanente em desempenho e financiamento, ao lado de uma assembléia representativa e deliberativa, como uma espécie de "parlamento das águas" nas esferas federal, estadual e municipal.

No Brasil os consórcios intermunicipais constituem uma associação entre prefeituras, empresas e sociedade civil com o objetivo de organizar e desenvolver projetos, serviços e ações de interesse comum; mas de forma alguma se assemelham às comissões locais de água - CLE - existentes na França. No Brasil, esses consórcios muitas vezes sofrem com a descontinuidade da gestão, seja por possíveis interrupções resultantes dos processos eleitorais ou mesmo pela inação por parte das esferas governamentais. Nesses fóruns, os integrantes não deveriam ter vínculos nem compromissos com interesses partidários, mas sim com a comunidade local e com a sociedade como um todo.

BRAGA, L.M.M.; ARGOLLO FERRÃO, A.M. A gestão dos recursos hídricos na França e no Brasil com foco nas bacias hidrográficas e seus sistemas territoriais. Labor \& Engenho, Campinas [SP] Brasil, v.9, n.4, p19-33, out./dez. 2015.

http://www.conpadre.org 


\section{Referências}

BRASIL, PRESIDÊNCIA DA REPÚBLICA. Congresso. Senado. Constituição (1988). Lei no 9.433, de 08 de janeiro de 1997. Institui a Política Nacional de Recursos Hídricos, cria o Sistema Nacional de Gerenciamento de Recursos Hídricos, regulamenta o inciso XIX do art. 21 da Constituição Federal, e altera o art. $1^{\circ}$ da Lei no 8.001, de 13 de março de 1990, que modificou a Lei no 7.990, de 28 de dezembro de 1989. Disponível em: http://www.planalto.gov.br/ccivil_03/LEIS/L9433.htm. — Acesso 21 jun. 2013.

BRASIL. Superintendência de Apoio à Gestão de Recursos Hídricos. Agência Nacional e Águas. Planos de recursos hídricos e enquadramento dos corpos de água: Cadernos de Capacitação em Recursos Hídricos. Brasília: Cedoc/biblioteca, 2011. 100 p. (V 5).

BRASIL. Plano Nacional de Recursos Hídricos: Síntese Executiva. Brasília, Ministério do Meio Ambiente, Secretaria de Recursos Hídricos. 2006.

BRASIL. Agência Nacional e Águas (Org.). Fundamentos Da Gestão Territorial Para Recursos Hídricos e Caracterização de Bacias Hidrográficas: Gestão Territorial para Recursos Hídricos com Software Livre de Código Aberto. Foz do Iguaçu: Cadernos de Capacitação. 2012. 27 p.

Disponível em https://www.aguaegestao.com.br/ead/course/view.php?id=673 — Acesso 11 jun. 2015.

DOS SANTOS, Cristiano Barbosa. Aos Trancos e Barrancos? A Eletrificação no Mundo Contemporâneo: Brasil, Um Retardatário? Fundação Energia e Saneamento. 2005. Disponível em http:// www.energiaesaneamento.org.br/media/63135/05.pdf - Acesso 14 abr. 2013.

FRANCE. France Nature Enviroment. La Gestion de L'Eau en France. 2008. Disponível em http:// www.fne.asso.fr/breves_pdf/eau/dossier_gestioneaufrance.pdf - Acesso 05 maio 2012.

GAZZANIGA, J.L.; OURLIAC, J.P.; LARROUY-CASTERA, X. L'eau: Usages et Gestion. Paris: Litec, 1998.

LITTLE, Paul E. Gestão Territorial em Terras Indígenas: Definição de Conceitos e Propostas de Diretrizes. RelatóRio Final. Secretaria de Estado de Meio Ambiente e Recursos Naturais (SEMA). Rio Branco. Acre. 2006. Disponível em www.kaninde.org.br/.../ gestao_territorial_em_terras_indagenas_133384 - Acesso 14 jun. 2015.

MARTINS, Rodrigo Constante. Sociologia da governança francesa das águas. Disponível em http:// www.scielo.br/scielo.php?pid=S010269092008000200007\&script=sci_arttext\#back — Acesso 06 nov. 2015.

MINAS GERAIS. Decreto no 44.199, de 29 de dezembro de de 2005.http://comites.igam.mg.gov.br/new/ index.php?option=com_content\&task=view\&id=15\&Itemid=398 - Acesso 04 mar. 2010.

SÃO PAULO. Consorcio PCJ. Quem é Quem. São Paulo, SP. Disponível em: http://agua.org.br/consorciopcj/ — Acesso 03 jul. 2014.

SÃO PAULO / IGC. UGRHI. Mapa das Unidades Hidrográficas de Gerenciamento de Recursos Hídricos. Disponível em: http://www.igc.sp.gov.br/produtos/ugrhi.html — Acesso 10 out. 2015.

TUCCI, Carlo E.C. Desenvolvimento dos Recursos Hídricos no Brasil. Global Water Partenership. 2004. 28p. Disponível em http://www.cepal.org/drni/proyectos/samtac/inbr00404.pdf - Acesso 05 ago. 2014. 